\title{
Kinetic Study of the Aldol Condensation of Isobutyraldehyde Catalyzed by Sodium Hydroxide
}

\author{
Wilhelm J. Tic \\ Department of Environmental Engineering, Opole University of Technology, Opole, Poland \\ Email:w.tic@po.opole.pl
}

How to cite this paper: Tic, W.J. (2016) Kinetic Study of the Aldol Condensation of Isobutyraldehyde Catalyzed by Sodium Hydroxide. Advances in Chemical Engineering and Science, 6, 456-469.

http://dx.doi.org/10.4236/aces.2016.64041

Received: May 30, 2016

Accepted: October 9, 2016

Published: October 12, 2016

Copyright $\odot 2016$ by author and Scientific Research Publishing Inc. This work is licensed under the Creative Commons Attribution International License (CC BY 4.0).

http://creativecommons.org/licenses/by/4.0/

\begin{abstract}
The initial step of works on the designing of a mathematical model of a commercial process to manufacture a mixture of butyric acid hydroxyesters, for use in ecological solvent compositions for the paint and varnish industry, is presented in the paper. The works referred to in this paper relate the mathematical model of the condensation reactor. A unit process kinetic model was designed based on an analysis of the general differential form of the equation of the reactor mass balance and an analysis of the mechanism of the Tishchenko aldol condensation reaction, as used in the synthesis of butyric acid hydroxyesters, confirmed by the results of GC/MS analysis. The forms of the kinetic equations obtained were verified experimentally by determining the values of the respective reaction rate constants.
\end{abstract}

\section{Keywords}

Tishchenko Reaction, Aldol Reaction, Kinetics

\section{Introduction}

Mathematical modelling is an extremely valuable tool that enables the dramatic effect of cost reduction to be achieved in the area of experimental works on the designing and development of chemical technology, taking change of scale into account. The ability to simulate the course of commercial processes in silico enables the real-time operation of a chemical plant to be simulated in the aspects of its entire mass balance, energy balance, and financial balance. The present paper relates to the designing of the kinetic model of the unit process of condensation.

\subsection{Application of Aldol Tishchenko Condensation}

The Tishchenko reaction, which is based on a series of methods to obtain esters from 
the respective aldehydes were developed, raises much interest due to its numerous useful advantages. After discovering its unique features, enabling the effect of stereoselectivity of its course to be obtained, the Tishchenko reaction was rediscovered and appreciated in the 1990's, specifically in connection with its features and applications in the synthesis of pure enantiomers, that had been demonstrated not long before.

A number of modified Tishchenko [1] reactions leading to various products, depending on the carbonyl substrate or type of catalysts used, are known.

In connection with the high reactivity of the aldehydes as their specific feature, it is necessary to select the suitable reaction conditions in planning the course of the synthesis in order to reduce the impact of side processes [2]-[4]. The most widely known side reactions, accompanying typical conditions of the Tishchenko reactions include: aldol condensation [5], Tollens reaction [6], Canizzaro reaction [7], oxidation by means of atmospheric air, transesterification [8], hydrolysis of reaction products [9], the Meerwein-Ponndorf-Verley reduction (MPV reduction) [10] [11], the Oppenauer oxidation reaction [12]. The equilibrium between the Tishchenko reaction and side reactions may be controlled by suitably selecting the catalyst, temperature, and type of solvent.

The reaction which is the subject of this characterization is also known as the Claisen-Tishchenko reaction in connection with the series of experiments with benzaldehyde and sodium alcoholates, carried out by Claisen in 1887. As mentioned earlier, the Tishchenko aldol condensation runs in the alkaline catalyst environment and concerns aldehydes having a hydrogen atom $\alpha$, determining the course of the aldol condensation. The reaction leads to the formation of monoesters of 1,3-diols.

Owing to its commercial importance, the above mentioned modification of the Tishchenko reaction has been investigated rather extensively [13]. The major reaction product is a mixture of isomers of 1,3-glycols, widely used as coalescents in the coating industry and as lubricants [14].

\subsection{Mechanism of Trimerization of Isobutanal}

The system of two isomeric esters of isobutyric acid is formed in the Tishchenko aldol condensation reaction, during which trimerisation of three molecules of isobutyric aldehyde occurs in accordance with the following general stoichiometric equation:

$$
3 \mathrm{C}_{4} \mathrm{H}_{8} \mathrm{O} \rightarrow \mathrm{C}_{12} \mathrm{H}_{24} \mathrm{O}_{3}
$$

The process of trimerisation starts with a reaction of two molecules of 2-methylbutanal, running according to the aldol condensation mechanism, leading to the formation of the aldol: 3-hydroxy-2,2,4-trimethylpentanal [15]-[18].

Based on the analysis of the possible reaction paths during the process of isobutanal condensation in the presence of an alkaline catalyst as well as experimental findings signalled in patent literature [19] and own research [20] [21], a series of reactions were selected as ones representing the most probable mechanism of isobutanal condensation, forecasting the occurrence of the following steps: 
1. Aldol condensation of 2 molecules of isobutanal.

1)

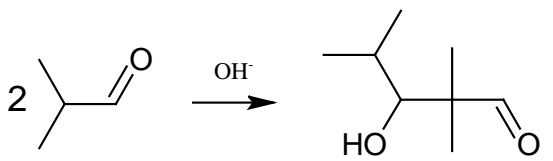

2. Condensation and disproportioning of isobutanal and aldol obtained in Reaction $1)$.

2)

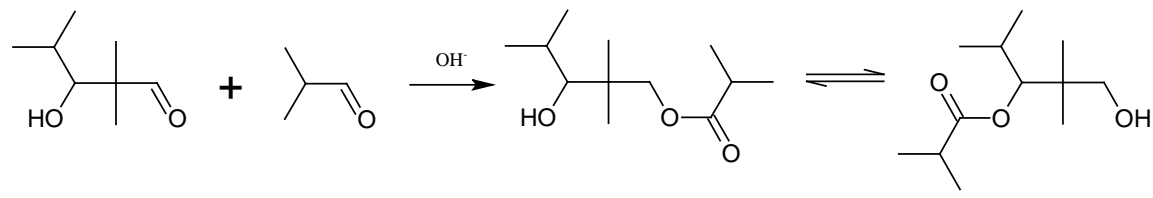

3. Transesterification with diester formation.

3)

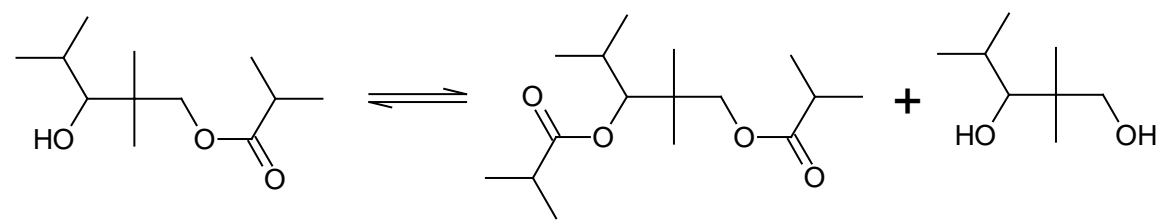

4. Partial hydrolysis of diester.

4)

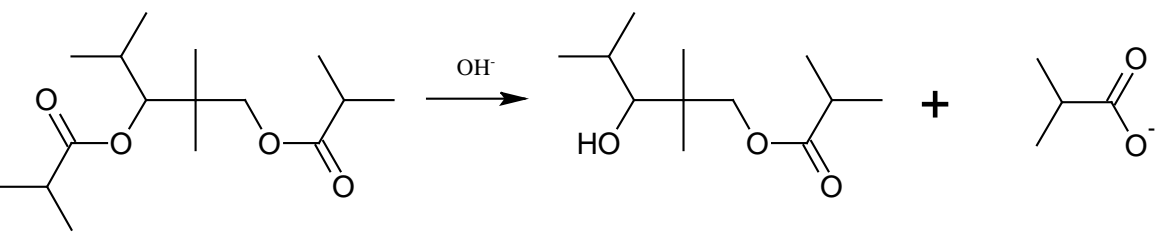

5. Hydrolysis of monoester.

5)

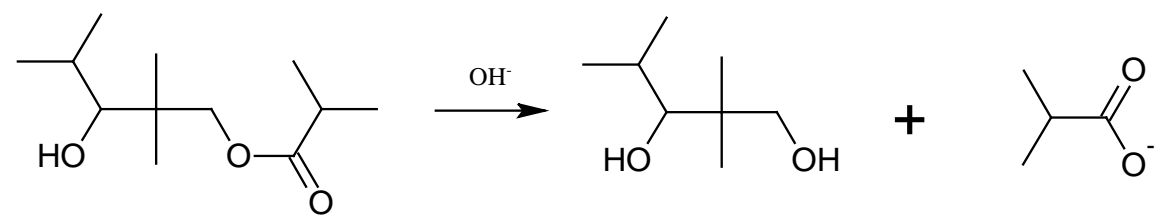

6. The Canizzaro reaction of the aldol obtained in step 3).

6) 2

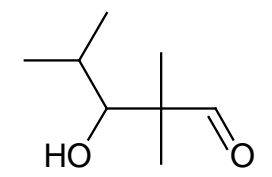<smiles>CC(C)C(O)C(C)(C)CO</smiles><smiles>CC(C)C(O)C(C)(C)C(=O)[O-]</smiles>

Acceptance of the proposed reaction mechanism for further studies is empirically justified by the findings of GC/MS analyses of samples of the reaction mixtures, collected from various steps of the process [14].

\section{Experimental}

\subsection{Raw Materials and Reagents}

Isobutanal (2-methylpropanal)-pure, from GA ZA Kędzierzyn.

3-Hydroxy-2,2,4-trimethylpentyl isobutyrate-pure, from Sigma-Aldrich. 
Sodium hydroxide, $40 \%$ solution-from POCH Gliwice S.A.

Acetic acid $80 \%$ pure, from POCH Gliwice S.A.

\subsection{Description of Apparatus and Method of Testing}

A thermostated $\left(60^{\circ} \mathrm{C}\right)$ reaction vessel with a weighed amount of post-reaction mixture was filled with a weighed amount of isobutyric aldehyde, and $2.7 \mathrm{~g}$ of $40 \% \mathrm{NaOH}$ solution was added to the obtained mixture. The resulting reaction mixture was stirred vigorously until the time $t$, was then placed in an ice bath whereafter $2.5 \mathrm{~g}$ of $80 \%$ acetic acid solution was added. The mixture was cooled down to a temperature in the range $15^{\circ} \mathrm{C}-20^{\circ} \mathrm{C}$ and analyzed by GC to determine the concentrations of the respective reacting substances.

The experiment was carried out for the times $t .2,4,8,15,30,60 \mathrm{~min}$, for reaction systems obtained by mixing 3-hydroxy-2,2,4-trimethylpentyl isobutyrate with isobutanal in quantitative ratios shown in Figure 4.

\section{Results and Discussion}

\subsection{Mass Balance of Continuous-Flow Tank Reactor}

Condensation of isobutyric aldehyde is performed in continuous-flow tank reactor equipped with efficient propeller or turbine type stirrer, providing fulfillment of kinetic criterion:

$$
t_{\text {mix }} \ll t_{1 / 2}
$$

where $t_{m i x}$ denotes mixing time and $t_{1 / 2}$ half-life time of reaction. In such conditions the isobutyric aldehyde condensation reactor may be approximated by an ideal continuousflow tank reactor model (Figure 1) described by continuity equation of its general differential form:

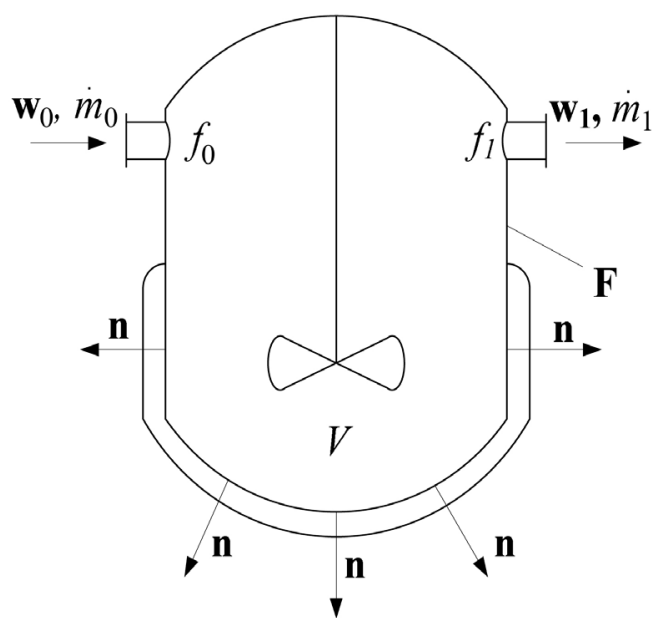

Figure 1. Scheme of ideal stirred continuous flow tank reactor. $W$-velocity (vector), $F$-surface, $V$ volume, $f_{0}$-reactor inlet surface, $f_{1}$-reactor outlet surface, $n$-oriented surface normal vector. 


$$
\frac{\partial \rho_{i}}{\partial t}=-\operatorname{div}\left(\rho_{i} \boldsymbol{w}+\boldsymbol{j}_{i}\right)+M_{i} \sum_{r=1}^{R} v_{r i} r_{r}
$$

where $\rho_{i}$ is density of $i$-component, $\boldsymbol{w}$-velocity field, $\boldsymbol{j}_{i}$-dispersion flow field of $i$, $M_{i}$-molecular weight of $i, v_{r i}$-stoichimetric factor of $i$ in reaction $r, r$-reaction rate, $R$-total number of reaction involved in process.

Integration of (3) over volume $V$ of reactor results Equation (4):

$$
\frac{\partial \rho_{i}}{\partial t} V=-\int_{V} \operatorname{div}\left(\rho_{i} \boldsymbol{w}+\boldsymbol{j}_{i}\right) \mathrm{d} V+V M_{i} \sum_{r=1}^{R} v_{r i} r_{r}
$$

Considering Gauss-Ostrogradsky theorem, volume integral of divergence appearing in (4) may be converted to the surface integral over the closed oriented boundary $F$.

$$
\int_{V} \operatorname{div}\left(\rho_{i} \boldsymbol{w}+\boldsymbol{j}_{i}\right) \mathrm{d} V=\oiint_{\boldsymbol{F}}\left(\rho_{i} \boldsymbol{w}+\boldsymbol{j}_{i}\right) \mathrm{d} \boldsymbol{F}
$$

where $\mathrm{d} \boldsymbol{F}=\boldsymbol{n} \cdot \mathrm{d} \boldsymbol{F}$ and $\boldsymbol{n}$ is surface normal vector.

Since the mass flows coming from the surface surrounding inside of reactor flow only through the surfaces $f_{0}$ and $f_{1}$, the surface integral (11) may be expressed by an algebraic sum of simple integrals as follows:

$$
\oiint_{\boldsymbol{F}}\left(\rho_{i} \boldsymbol{w}+\boldsymbol{j}_{i}\right) \mathrm{d} \boldsymbol{F}=\int_{f_{0}}\left(\rho_{i} \boldsymbol{w}+\boldsymbol{j}_{i}\right) \mathrm{d} \boldsymbol{F}+\int_{f_{1}}\left(\rho_{i} \boldsymbol{w}+\boldsymbol{j}_{i}\right) \mathrm{d} \boldsymbol{F}
$$

Assuming the field of $i$-compound velocity on surfaces $f_{0}$ and $f_{1}$ equals the barycentric velocity and then in consequence negligibility of dispersion flow of $i$, what could be expressed by criteria:

$$
\boldsymbol{w}=\boldsymbol{w}_{i} \Rightarrow \boldsymbol{j}_{i}=\rho_{i}\left(\boldsymbol{w}_{i}-\boldsymbol{w}\right)=0
$$

then

$$
\int_{f_{0}}\left(\rho_{i} \boldsymbol{w}+\boldsymbol{j}_{i}\right) \mathrm{d} \boldsymbol{F}+\int_{f_{1}}\left(\rho_{i} \boldsymbol{w}+\dot{j}_{i}\right) \mathrm{d} \boldsymbol{F}=-\rho_{0} w_{0} f_{0}+\rho_{1} w_{1} f_{1}=\dot{m}_{1}-\dot{m}_{0}=\Delta \dot{m}
$$

In view of (10) and (14), assuming the process runs in condition of non-compressible fluid, the mass balance of continuous-flow tank reactor may be expressed by model equation, applicable for engineering purposes:

$$
\dot{m}_{1}-\dot{m}_{0}=V M_{i} \sum_{r=1}^{R} v_{r i} r_{r}
$$

where $\dot{m}_{0}$ and $\dot{m}_{1}$ are inlet and outlet mass flows respectively.

Considering the presence of the kinetic member in model Equation (9), in order to determine its form, an analysis of the isobutanal condensation reaction kinetics was performed as it follows below.

\subsection{Kinetics of Trimerization of Isobutanal}

Acceptance of the proposed reaction mechanism for further studies, step 1)-6), is empirically justified by the findings of GC/MS analyses of samples of the reaction mixtures, collected from various steps of the process.

Figure 2 shows the GC/MS chromatogram of the reaction mixture "frozen" sample 


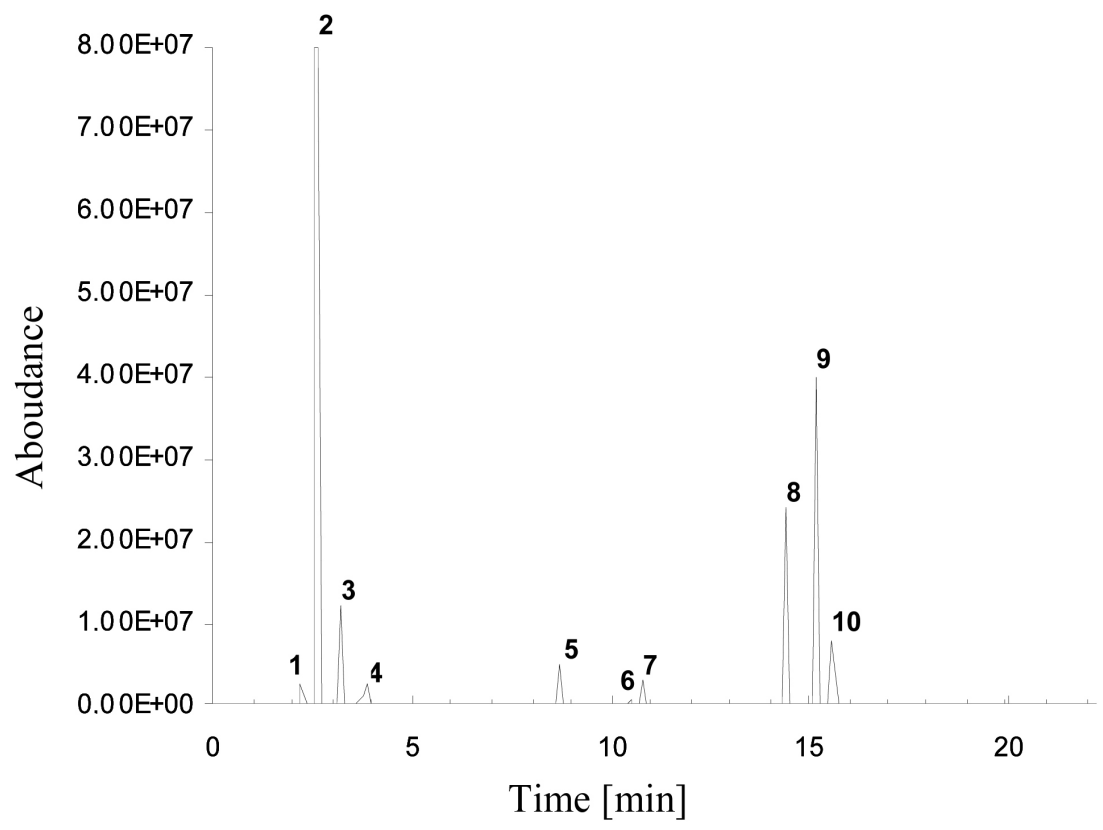

Figure 2. The GC/MS chromatogram of isobutanal condensation reaction mixture sample, "frozen" after 1 min of reaction time. 1-water, 2-isobutanal, 3-2-methyl-2propen-1-ol, 4-isobutyric acid, 5-3-hydroxy-2,2,4-trimethylpenthanal, 6-2,4,6triisopropyl-1,3,5-trioxane, 7-2,2,4-trimethylpenthane-1,3-diol, 8-5,5-dimethylo2,6-diisopropyl-1,3-dioxane-4-ol or 3-(1-hydroxy-2-methylopropoxy)-2,2,4-trimethylpenthanal, 9, 10-2,2,4-trimethylpenthane-1,3-diol monoisobutyrates (isomers).

collected after 1 min of reaction.

Significant feature of the shape of this chromatographic curve occurs to be an appearance of peaks characteristic for the presence of mentioned above system hemiacetale/dioxanole and transitional aldole reaction product of 2 moles of isobutanal: 2-hydroxy-2,2,4-trimethylpentanal. As it has been already stated, both undergo consequent Tishchenko reaction, what finds reflection in the shape of the chromatogram of the sample of post reaction mixture (Figure 3 ).

The shape of post reaction mixture sample proves the decay of transitional by products of Tishchenko reaction appearing at initial stages of reaction, hemiacetale/dioxanole system and 2-hydroxy-2,2,4-trimethylpentanal, which underwent esterification through the reaction run, according to the Tishchenko reaction mechanism scheme signaled earlier.

\subsubsection{Formulation of the Kinetic Model of Isobutanal Condensation}

Assuming the constant concentration of the catalyst, the following kinetic equation for the reaction described by step 1)-6) was formulated:

$$
\frac{\mathrm{d}}{\mathrm{d} t} \boldsymbol{C}=\boldsymbol{v}^{\mathrm{T}} \cdot \boldsymbol{r}
$$

where:

$$
C \text {-reagents concentration column matrix, } \mathrm{mol} \cdot \mathrm{dm}^{-3} \text {. }
$$




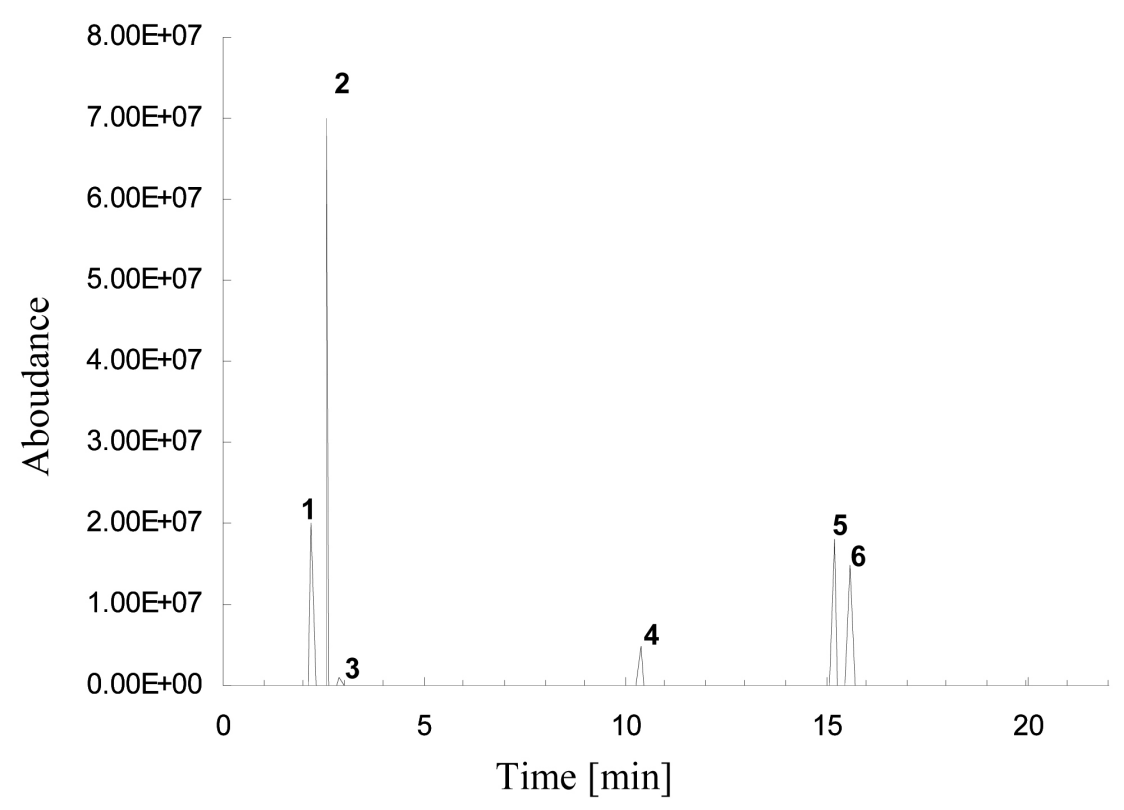

Figure 3. The GC/MS chromatogram of isobutanal condensation reaction mixture sample after completion of reaction. 1-water, 2-isobutanal, 3-isobutyric acid, 42,2,4-trimethylpenthane-1,3-diol, 5, 6-2,2,4-trimethylpenthane-1,3-diol monoisobutyrates (isomers).

$v^{\mathrm{T}}$-transpose of chemical matrix of the reaction system.

$\boldsymbol{r}$-condensation process component reactions rates equations column matrix, $\mathrm{mol} \cdot \mathrm{dm}^{3} \cdot \mathrm{min}^{-1}$.

Referring to the results of preliminarily carried out investigations of the reaction mixture compositions, showing negligibly low values of concentration of some components of these mixtures, it may be concluded the composition of the reaction mixture in conditions of the industrial reactor run will be determined only by the process described by step 1), 2) and 5). Therefore, the general kinetic Equation (10) may be formulated as follows:

$$
\frac{\mathrm{d}}{\mathrm{d} t}\left[\begin{array}{l}
a \\
b \\
c
\end{array}\right]=\left[\begin{array}{cc}
-3 & 0 \\
1 & -1 \\
0 & 1
\end{array}\right] \cdot\left[\begin{array}{l}
r_{1} \\
r_{2}
\end{array}\right]
$$

where:

a-isobutanal concentration, $\mathrm{mol} \cdot \mathrm{dm}^{-3}$.

$b$-3-hydroxy-2,2,4-trimethylpentyl isobutyrate (the sum of both isomers) concentration, $\mathrm{mol} \cdot \mathrm{dm}^{-3}$.

c-concentration of 2,2,4-trimethyl-1,3-penthanodiole, mol. $\mathrm{dm}^{-3}$.

$r_{1}$-sum of reaction (4) and (5) rate, $\mathrm{mol} \cdot \mathrm{dm}^{-3} \cdot \mathrm{min}^{-1}$.

$r_{2}$-reaction (8) rate, $\mathrm{mol} \cdot \mathrm{dm}^{-3} \cdot \mathrm{min}^{-1}$.

$$
\begin{aligned}
& r_{1}=k_{1} a^{3} \\
& r_{2}=k_{2} b
\end{aligned}
$$


where:

$k_{1}$-isobutanal trimerisation reaction rate constant.

$k_{2}$-hydrolysis reaction, step 4) rate constant.

Solution of the first member of ordinary differential equation system (11) using the separation of variables method results the particular integral of irrational form:

$$
a(t)=\frac{a_{0}}{\sqrt{6 \cdot a_{0} \cdot k_{1} \cdot t+1}} .
$$

Solution of ordinary differential equation (ODE):

$$
\frac{\mathrm{d}}{\mathrm{d} t} b(t)=\frac{k_{1} a_{0}^{3}}{\left(6 \cdot a_{0} \cdot k_{1} \cdot t+1\right)^{3 / 2}}-k_{2} b(t)
$$

was obtained by Laplace transformation:

$$
\hat{L}\left[\frac{\mathrm{d}}{\mathrm{d} t} b(t)\right]=\hat{L}\left[\frac{k_{1} a_{0}^{3}}{\left(6 \cdot a_{0} \cdot k_{1} \cdot t+1\right)^{3 / 2}}-k_{2} b(t)\right]
$$

where:

$$
\hat{L} f(t)=\int_{0}^{\infty} f(t) \mathrm{e}^{-s t} \mathrm{~d} t
$$

and $s$ is complexed variable defined as: $s=x+i y$.

Result of solution of step 1) obtained after inversion of transformation 2) may be expressed by following equation:

$$
b(t)=\frac{A \cdot f(t) \cdot \mathrm{e}^{g(t)}+B \cdot \operatorname{erf}[h(t)]+C}{\mathrm{e}^{k_{2} t}}
$$

where:

$$
\begin{gathered}
A=\frac{\mathrm{e}^{\frac{-k_{2}}{6 a_{0}^{2} \cdot k_{1}}}}{3 \cdot a_{0}^{2} \cdot k_{1}} \\
B=\frac{k_{2} \sqrt{\pi}}{a_{0} \cdot k_{1} \cdot \sqrt{\frac{-6 \cdot k_{2}}{k_{1}}}} \\
f(t)=-\left(6 \cdot a_{0}^{2} \cdot k_{1} \cdot t+1\right)^{-\frac{1}{2}} \\
g(t)=\frac{k_{2}}{6 \cdot a_{0}^{2} \cdot k_{1}}\left(6 \cdot a_{0}^{2} \cdot k_{1} \cdot t+1\right) \\
h(t)=\frac{1}{a_{0}} \cdot \sqrt{-\frac{k_{2}}{6 \cdot k_{1}}} \cdot \sqrt{6 \cdot a_{0}^{2} \cdot k_{1} \cdot t+1}
\end{gathered}
$$

The solution procedure of ODE (15) referred to function $b(t)$ met some inconveniences connected with the properties of Laplace transformation and limited possibility of extraction of complex forms of transform inversions. In order to convert imaginary function $B \cdot \operatorname{erf}[h(t)]$ to the real form, the conversion of complex expressions (19) 
and (20) was carried out to obtain respectively:

$$
B=-\frac{k_{2} \sqrt{\pi}}{a_{0} \cdot k_{1} \cdot \sqrt{\frac{6 \cdot k_{2}}{k_{1}}}} \cdot i .
$$

And

$$
h(t)=\frac{1}{a_{0}} \cdot \sqrt{\frac{k_{2}}{6 \cdot k_{1}}} \cdot \sqrt{6 \cdot a_{0}^{2} \cdot k_{1}+1} \cdot i
$$

what allowed to introduce substitution:

$$
i \cdot \operatorname{erf}[i \cdot f(t)]=\operatorname{erfi}[f(t)]
$$

where erfi $[f(t)]$ denotes imaginary error function, expandable to convergent Maclaurin's series [22]:

$$
\operatorname{erfi}(z)=\frac{2}{\sqrt{\pi}} \sum_{n=1}^{\infty} \frac{z^{(2 n-1)}}{[2 n-1] \cdot[(n-1) !]} .
$$

Introduction of the series (27) made possible to output results of calculations using Equation (18) in the real range. Because of the difficulties with performance of the Laplace transformation (17) on expression (18) the analytical solution of (11) vs. concentration of diole was not been obtained.

The Equation (11) was also solved numerically using Runge-Kutta method [23].

Figure 4 shows the curves expressing the changes of the concentrations of isobutanal, hydroxyester and diol in time of reaction, constituting the kinetic model of the isobutanal condensation process. The following solution was achieved assuming initial concentration of isobutanal $a_{0}=11.0 \mathrm{~mol} \cdot \mathrm{dm}^{-3}$ and initial concentration of hydroxyester $b_{0}=0.5 \mathrm{~mol} \cdot \mathrm{dm}^{-3}$.

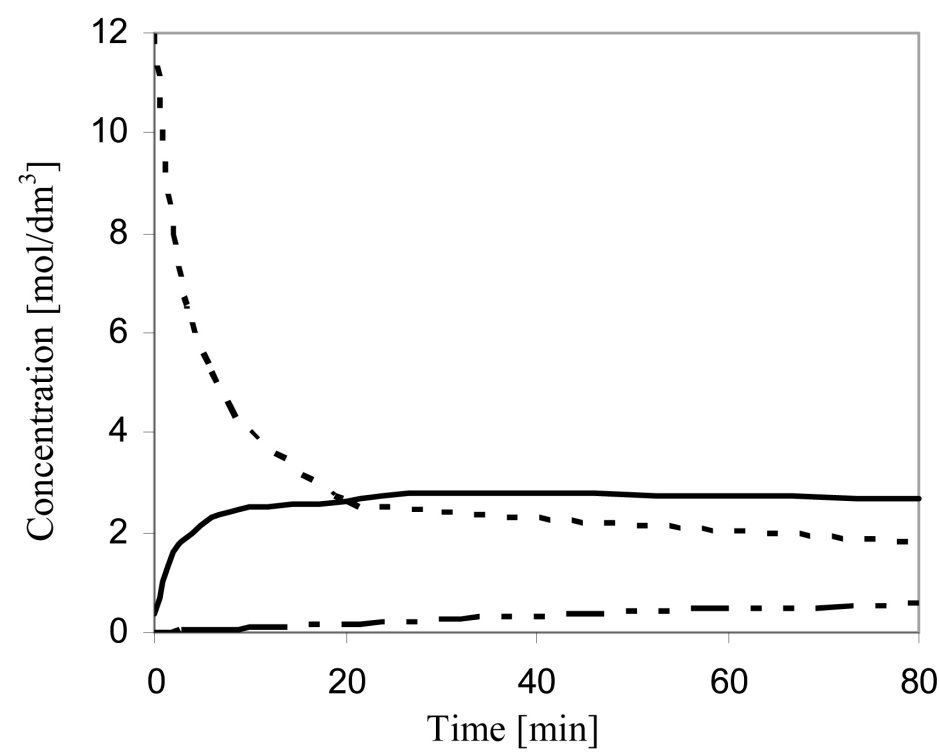

Figure 4. The plot of isobutanal condensation kinetic model. 
The course of the curve of changes of the concentration of the hydroxyester indicates the presence, in the environment of the point of time $t=45 \mathrm{~min}$, of a stationary point which is characterized by a maximum concentration of the hydroxyester. After the time is exceeded, the course of the model curve shows a decrease in the concentrations of the hydroxyester, which is both due to the reaction getting slower at lower concentrations of isobutanal and due to the course of the side reaction of hydrolysis of which the rate does not depend on the concentration of isobutanal. The last reaction is accompanied by an increase in the concentration of the diol. In the aspect of process kinetics and the purity of final product, leading to a reduction in capital expenditure and process costs connected with the utilization of the diol, the optimal time range of $10-20 \mathrm{~min}$ of the residence of the reaction mixture in the reaction zone is of commercial value.

\subsubsection{Test Results, Verification of Adopted Kinetic Model}

In order to verify the adopted kinetic model, as described by the system of differential Equation (11), the measurement points obtained during kinetic tests were approximated by means of curves obtained by solving Equation (11) numerically, by minimizing the sums of squared deviations between the values predicted by the model and those obtained experimentally.

Figures 5-9 show the graphs of dependence of the concentrations of isobutanal, hydroxyester, and diol vs. time, on which the values of the measurement points obtained during the experiments were plotted along with the curves which are approximations of experimental results, obtained by means of general integrals of Equation (11).

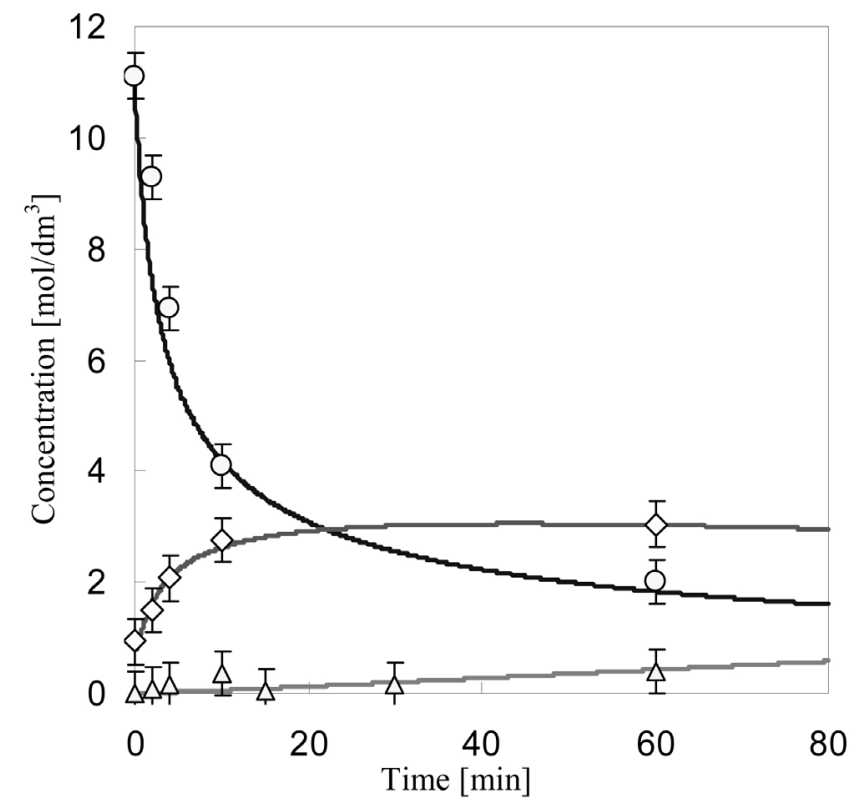

Figure 5. The plot of experimental and model kinetic data for isobutanal, hydroxyester and diol. $a_{0}=11.00 \mathrm{~mol} / \mathrm{l}, b_{0}=0.90$ $\mathrm{mol} / \mathrm{l} ; \diamond$-hydroxyester HE1 (2,2,4-trimethylpentane-1,3-diol monoisobutyrates mixture); O-isobutanal (2-methylopropanal); $\triangle$-2,2,4-trimethylpentane-1,3-diol. 


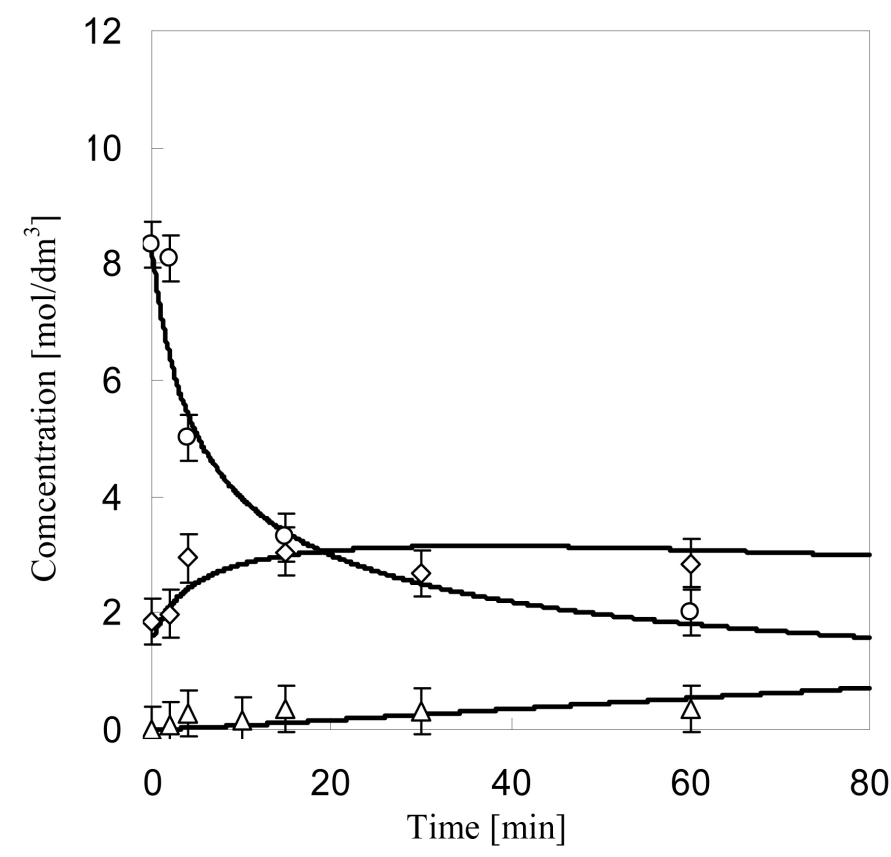

Figure 6. The plot of experimental and model kinetic data for isobutanal, hydroxyester and diol. $a_{0}=8.30 \mathrm{~mol} / 1, b_{0}=1.80 \mathrm{~mol} / \mathrm{l} ; \diamond-$ hydroxyester HE1 (2,2,4-trimethylpentane-1,3-diol monoisobutyrates mixture); O-isobutanal (2-methylopropanal); $\Delta-2,2,4$-trimethylpentane-1,3-diol.

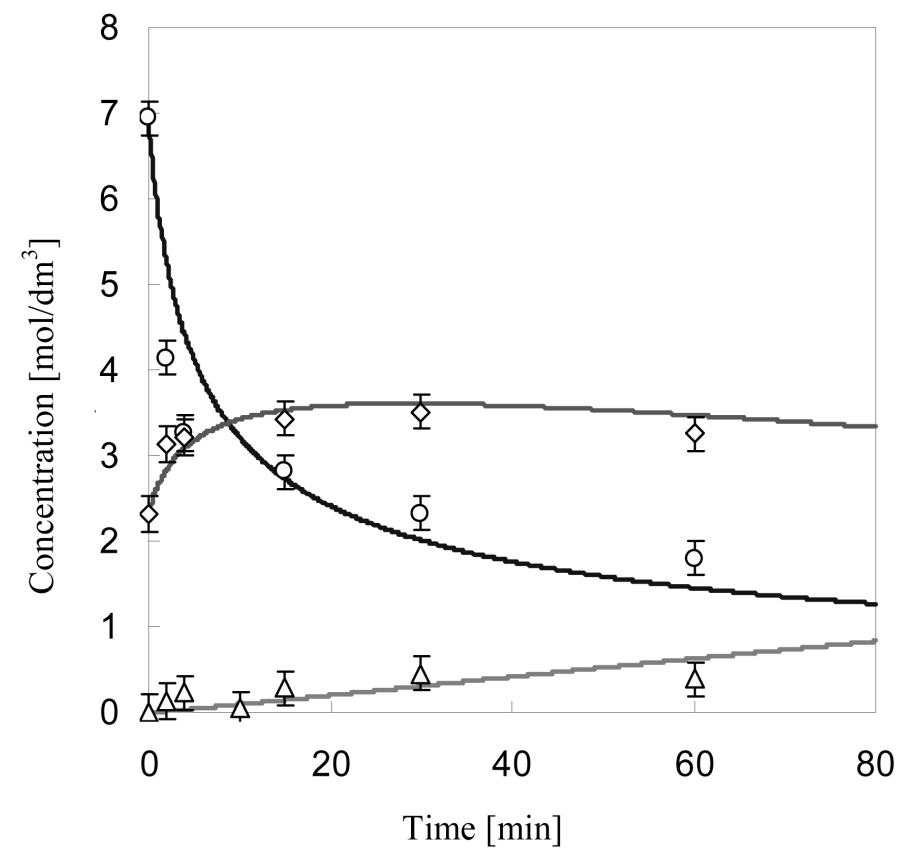

Figure 7. The plot of experimental and model kinetic data for isobutanal, hydroxyester and diol. $a_{0}=6.94 \mathrm{~mol} / 1, b_{0}=2.30 \mathrm{~mol} / \mathrm{l} ; \diamond$-hydroxyester HE1 (2,2,4-trimethylpentane-1,3-diol monoisobutyrates mixture); O-isobutanal (2-methylopropanal); $\Delta$-2,2,4-trimethylpentane-diol. 


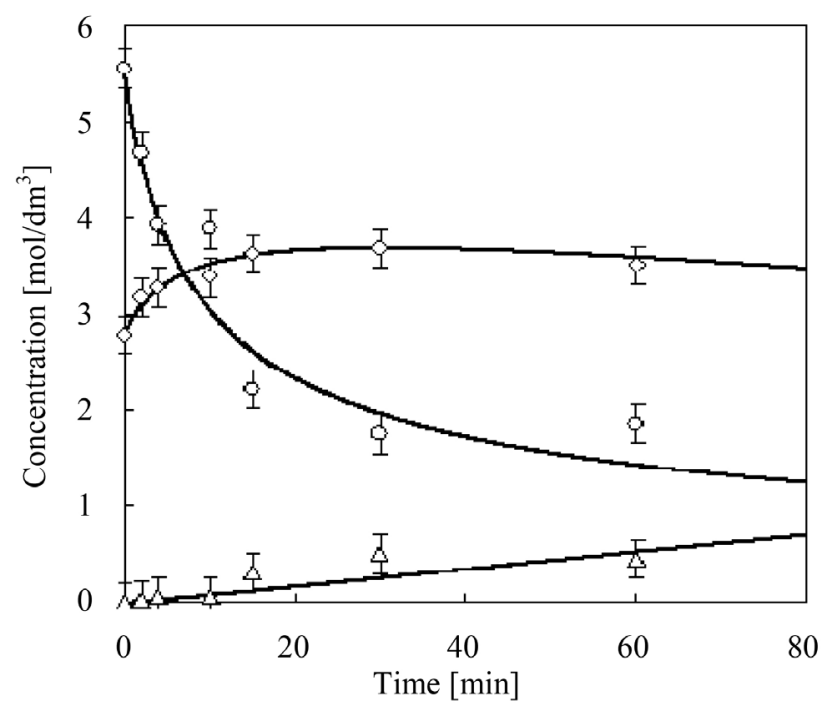

Figure 8. The plot of experimental and model kinetic data for isobutanal, hydroxyester and diol. $a_{0}=5.56 \mathrm{~mol} / 1, b_{0}=2.80 \mathrm{~mol} / \mathrm{l}$; $\diamond$-hydroxyester HE1 (2,2,4-trimethylpentane-1,3-diol monoisobutyrates mixture); O-isobutanal (2-methylopropanal); $\Delta-$ 2,2,4-trimethylpentane-1,3-diol.

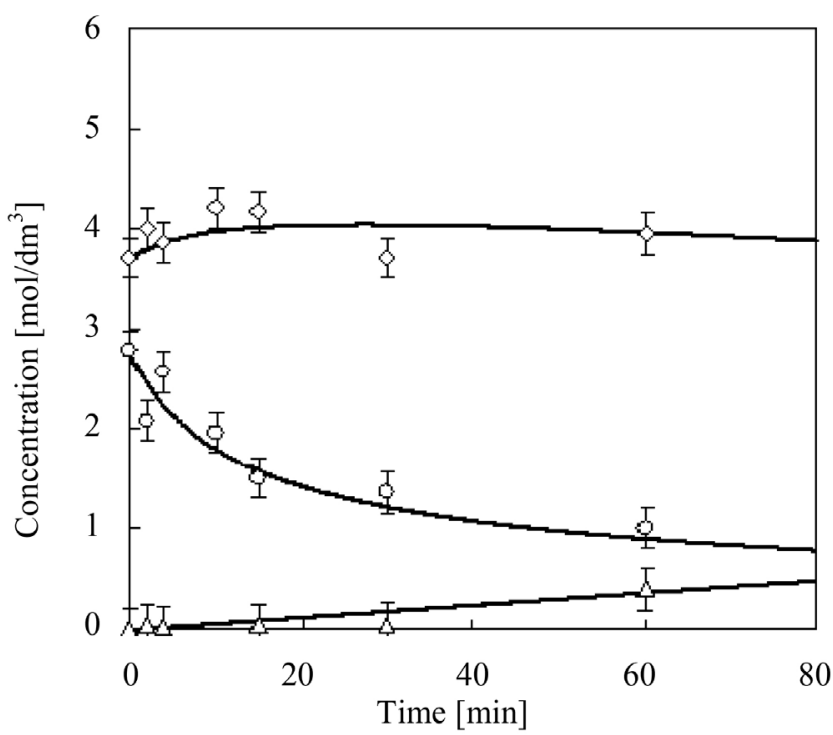

Figure 9. The plot of experimental and model kinetic data for isobutanal, hydroxyester and diol. $a_{0}=2.78 \mathrm{~mol} / 1, b_{0}=3.70 \mathrm{~mol} / \mathrm{l}$; $\diamond$-hydroxyester HE1 (2,2,4-trimethylpentane-1,3-diol monoisobutyrates mixture); O-isobutanal (2-methylopropanal); $\Delta-$ 2,2,4-trimethylpentane-1,3-diol.

The shape of the curves, their location, as well as the results of analysis of remainders indicate a high adequacy of the adopted model of the process kinetics of catalytic condensation of isobutanal, validating the assumptions with regard to the decisive processes and their stoichiometries, with an accuracy of the value of the sum of the remain- 
ders. It is safe to assume that the resulting model adequacy is sufficient for engineering applications, specifically in the stages of designing, scale development, and optimization of the operation of the condensation reactor. The reaction rate constants were: $k_{1}=$ $0.00122 \mathrm{l}^{2} \cdot \mathrm{mol}^{-2} \cdot \mathrm{min}^{-1} ; k_{2}=0.0035 \mathrm{~min}^{-1}$, respectively.

\section{Conclusion}

The analysis of the mechanism of isobutanal condensation that was carried out indicates the possibility of assumption that the process may run in a single step of trimerization of three molecules of the aldehyde to 2,2,4-trimethyl-1,3-pentanediol 2-methylpropionate, and that the side reaction of product hydrolysis produces 2,2,4-trimethyl1,3-pentanediol. Based on experimental findings, the kinetic equation of the aldol homocondensation of isobutanal was formulated as the dependence of reaction rate vs. time. The set of kinetic equations was solved by independent mathematical and numerical methods. Measurement points, obtained during kinetic studies, were approximated with experimentally obtained values in order to verify the adopted kinetic model. A high adequacy of the adopted kinetic model of the isobutanal condensation process was obtained as the result. Reaction rate constants were found for competitive reactions, determining the process yields, i.e., those of trimerization and hydrolysis, which were $k_{1}=$ $0.00122\left(\mathrm{dm}^{3}\right)^{2} \cdot \mathrm{mol}^{-2} \cdot \mathrm{min}^{-1} ; k_{2}=0.0035 \mathrm{~min}^{-1}$, respectively.

\section{Acknowledgements}

This research work was financed as a $R \& D$ project No. 13856, with the support of National Research and Development Centre, Poland.

\section{References}

[1] Koskinen, A.M.P. and Kataja, A.O. (2015) The Tishchenko Reaction. Organic Reactions, 86, 105-410. http://dx.doi.org/10.1002/0471264180.or086.02

[2] Xu, H.-F., Zhong, H., Wang, S. and Li, F.-X. (2015) One-Pot Synthesis of Cyclic Aldol Tetramer and $\alpha, \beta$-Unsaturated Aldol from Linear Aldehydes Using Quaternary Ammonium Combined with Sodium Hydroxid as Catalysts. Journal of Central South University, 22, 2081-2087. http://dx.doi.org/10.1007/s11771-015-2732-2

[3] Cota, B.I., Gonzalez-Olmos, R., Iglesias, M. and Medina, F. (2013) New Brønsted Ionic Liquids: Synthesis, Thermodinamics and Catalytic Activity in Aldol Condensation Reactions. In: Kadokawa, J., Ed.

[4] Liao, Y.-X., Xing, Ch.-H., Israel, M. and Hu, Q.-S. (2011) Sequential Aldol CondensationTransition Metal-Catalyzed Addition Reactions of Aldehydes, Methyl Ketones, and Arylboronic Acids. Organic Letters, 13, 2058-2061. http://dx.doi.org/10.1021/ol200457q

[5] Casey, C.P. and Whiteker, G.T. (1990) The Natural Bite Angle of Chelating Diphosphines. Israel Journal of Chemistry, 30, 299-304. http://dx.doi.org/10.1002/ijch.199000031

[6] March, J. (1993) Advanced Organic Chemistry; Reaction, Mechanisms and Structure. 4th Edition, Wiley \& Sons.

[7] Kharasch, M.S. and Snyder, R.H. (1949) Studies Pertaining to the Mechanism of the Heterogeneous Cannizzaro Reaction. Journal of Organic Chemistry, 14, 819-835. http://dx.doi.org/10.1021/jo01157a015 
[8] Otera, J., Yano, T., Kawabata, A. and Nozaki, H. (1986) Novel Distannoxane-Catalyzed Transesterification and a New Entry to a,b-Unsaturated Carboxylic Acids. Tetrahedron Letters, 27, 2383-2386. http://dx.doi.org/10.1016/S0040-4039(00)84535-9

[9] Bowden, K. (1995) Intramolecular Catalysis: Carbonyl Groups in Ester Hydrolysis. Chemical Society Reviews, 24, 431-435. http://dx.doi.org/10.1039/cs9952400431

[10] de Graauw, C.F., Peters, J.A., van Bekkum, H. and Huskens, J. (1994) Meerwein-PonndorfVerley Reductions and Oppenauer Oxidations: An Integrated Approach. Synthesis, 10, 1007-1017. http://dx.doi.org/10.1055/s-1994-25625

[11] Sushkevicha, V.L., Ivanova, I.I., Tolborgc, B.S. and Esben Taarningc, E. (2014) MeerweinPonndorf-Verley-Oppenauer Reaction of Crotonaldehyde with Ethanol over Zr-Containing Catalysts. Journal of Catalysis, 316, 121-129. http://dx.doi.org/10.1016/j.jcat.2014.04.019

[12] Woodward, R.B., Wendler, N.L. and Brutschy, F.J. (1945) Quininone. Journal of the American Chemical Society, 67, 1425-1430. http://dx.doi.org/10.1021/ja01225a001

[13] Kirk-Othmer Encyklopedia of Chemical Technology, 3rd Edition, 966.

[14] Tic, W.J. (2005) Conversion of 2-Methylpropanal toward Aliphatic Solvents and Plasticizers for Polymers. Przemysł Chemiczny, 1, 32-35.

[15] Migues, A.N., Vaitheeswaran, S. and Auerbach, S.M. (2014) Density Functional Theory Study of Mixed Aldol Condensation Catalyzed by Acidic Zeolites HZSM-5 and HY. Journal of Physical Chemistry C, 118, 20283-20290. http://dx.doi.org/10.1021/jp504131y

[16] Villani, F.J. and Nord, F.F. (1946) Glycol Esters from Aldehydes. Journal of the American Chemical Society, 68, 1674-1675. http://dx.doi.org/10.1021/ja01212a519

[17] Fouquet, G., Merger, F. and Platz, R. (1979) Über die. Tischtschenko-Reantion von Aldolen. European Journal of Organic Chemistry, 1979, 1591-1601.

[18] Spät, R., Lorenz, R. and Freund, E. (1943) Über ein Additionsprodukt des Acetaldehyds an Acetaldol (V. Mitteil. über Derivate des Aldols und des Crotonaldehyds). European Journal of Inorganic Chemistry, 76, 57-68. http://dx.doi.org/10.1002/cber.19430760107

[19] Molander, G.A. and Etter, J.B. (1987) Lanthanides in Organic Synthesis. 8. 1.3-Asymmetric Induction in Intramolecular Reformatskii-Type Reactions Promoted by Samarium Dioxide. Journal of the American Chemical Society, 109, 6556-6558. http://dx.doi.org/10.1021/ja00255a076

[20] Beller, M., Cornils, B., Frohning, C.D. and Kohlpaintner, C.W. (1995) Progress in Hydroformylation and Carbonylation. Journal of Molecular Catalysis A, 104, 17-85. http://dx.doi.org/10.1016/1381-1169(95)00130-1

[21] Li, Y.-G., Luo, C.-X., Qian, C. and Chen, X.-Z. (2013) Trimerization of Aldehydes with One $\alpha$-Hydrogen Catalyzed by Sodium Hydroxide. Chemical Papers, 68, 422-426.

[22] Luke, Y.L. (1969) The Special Functions and Their Approximations. Academic Press, New York.

[23] Rice, R.G. (1995) Applied Mathematics and Modeling for Chemical Engineers. Wiley \& Sons, New York. 
Submit or recommend next manuscript to SCIRP and we will provide best service for you:

Accepting pre-submission inquiries through Email, Facebook, LinkedIn, Twitter, etc. A wide selection of journals (inclusive of 9 subjects, more than 200 journals)

Providing 24-hour high-quality service

User-friendly online submission system

Fair and swift peer-review system

Efficient typesetting and proofreading procedure

Display of the result of downloads and visits, as well as the number of cited articles

Maximum dissemination of your research work

Submit your manuscript at: http://papersubmission.scirp.org/

Or contact aces@scirp.org 